\title{
Successful Percutaneous Drainage with lodine Irrigation for Pancreatic Fistulas and Abscesses after Necrotizing Pancreatitis
}

\author{
Enver Zerem ${ }^{a}$ Safet Omerović ${ }^{b}$ \\ a University Clinical Center Tuzla, Tuzla, and ${ }^{\text {b }}$ General Hospital Mostar, Mostar, Bosnia and Herzegovina
}

\section{Key Words}

Pancreatic fistula Pancreatic abscess $\cdot$ Infected pancreatic necrosis

\begin{abstract}
Objective: To report an uncommon method of managing pancreatic fistulas and retroperitoneal abscess. Clinical Presentation and Intervention: A 50-year-old man was admitted with fever, abdominal pain, periumbilical fistula and pus in stool. Five months before admission, he underwent urgent necrosectomy (7 days after onset of pain) and subsequently two more surgeries for necrotizing pancreatitis. UItrasound revealed fluid collection in the retropancreatic space. After evacuation of pus, contrast medium instilled through a catheter showed a retroperitoneal abscess cavity, retroperitoneal-periumbilical and retroperitoneal-sigmoidal fistulas. After percutaneous drainage and iodine irrigation, the abscess collection and fistulas disappeared. Conclusion: In this case, percutaneous drainage was a successful option in the management of pancreatic fistulas and a retroperitoneal abscess.

Copyright $\odot 2012$ S. Karger AG, Basel
\end{abstract}

\section{Introduction}

Several authors consider open surgery and immediate surgical necrosectomy to be the gold standard of procedures for patients with infected pancreatic necrosis $[1,2]$ due to their effectiveness in sepsis control. However, other reports have shown that early surgical intervention for pancreatic necrosis could result in a poor clinical outcome. Moreover, surgery has been associated with the development of complications, such as infected pancreatic collections and fistulas [3-5].

A pancreatic fistula is usually a complication linked to acute and chronic pancreatitis, but can also occur postoperatively or after abdominal trauma. Surgery is necessary in a minority of cases when conservative treatment or endoscopy has failed or if either was not technically possible $[6,7]$.

We report our experience with a patient with retroperitoneal abscess and retroperitoneal-periumbilical and retroperitoneal-sigmoidal fistulas formed after immediate surgical necrosectomy who underwent successful percutaneous drainage under ultrasound guidance. To the best of our knowledge, this method of treating pancreatic fistulas has not been described in the available literature.

\section{KARGER \\ Fax +41613061234 \\ E-Mail karger@karger.ch}

www.karger.com
(C) 2012 S. Karger AG, Basel

1011-7571/12/0214-0398\$38.00/0

Accessible online at: www.karger.com/mpp
Zerem Enver

University Clinical Center Tuzla

Trnovac bb

BA-75000 Tuzla (Bosnia and Herzegovina)

Tel. +387 6234 4293, E-Mail zerem@live.com 


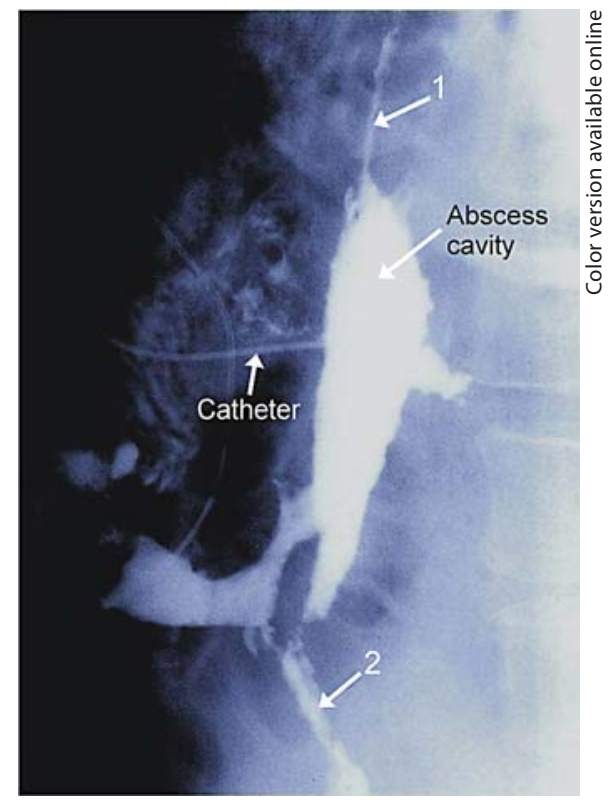

Fig. 1. Abscess collection in retropancreatic space. Retroperitoneal abscess collection cavity with two fistulas. Arrow 1: cutaneous fistula; arrow 2: retroperitoneal-sigmoidal fistula.

\section{Case Report}

A 50-year-old man was transferred from General Hospital Mostar and admitted in poor general condition with fever, abdominal pain, periumbilical fistula and presence of pus in the stool. A cutaneous fistula was producing about $200 \mathrm{ml}$ of pus per day. Five months before admission to our hospital he had undergone urgent laparotomy and necrosectomy (7 days after onset of pain) for acute infected necrotizing pancreatitis. Subsequently, the patient underwent two more surgical interventions due to the collection of retroperitoneal fluid containing pus and necrosis. After the third surgery, the cutaneous perumbilical fistula still persisted. Two weeks before being admitted to our hospital the patient noted pus in his stool.

Laboratory tests showed an elevated level of erythrocyte sedimentation rate of $135 \mathrm{~mm} / \mathrm{h}$ (normal <10), C-reactive protein $326 \mathrm{mg} / \mathrm{l}$ (normal <3.3), fibrinogen $12.4 \mathrm{~g} / \mathrm{l}$ (normal 1.8-3.5), WBC $19,000 / \mathrm{mm}^{3}$, neutrophils $16,340 / \mathrm{mm}^{3}$, platelets $280,000 /$ $\mathrm{mm}^{3}$, serum total bilirubin $61 \mu \mathrm{mol} / 1$ (normal 3.4-20.5), aspartate aminotransferase $73 \mathrm{U} / 1$ (normal 5-34), alanine aminotransferase $144 \mathrm{U} / 1$ (normal 0-55), alkaline phosphatase $396 \mathrm{U} / 1$ (normal 50-136), gamma-glutamic transpeptidase $440 \mathrm{U} / \mathrm{l}$ (normal 9-64), total protein $61 \mathrm{~g} / \mathrm{l}$, albumin $21 \mathrm{~g} / \mathrm{l}$, globulin $40 \mathrm{~g} / \mathrm{l}$, BUN $8.8 \mathrm{mmol} / \mathrm{l}$ (normal 2-7.5), glucose $23.5 \mathrm{mmol} / \mathrm{l}$ (normal 3.5-5.5), and creatinine $140 \mu \mathrm{mol} / \mathrm{l}$ (normal 40-90).

Ultrasound investigation revealed a large abscess collection in the retropancreatic space. A catheter was introduced under ultrasound guidance to evacuate about $200 \mathrm{ml}$ of pus. After evacuation of the pus, a contrast medium was instilled through the catheter. It showed a retroperitoneal abscess cavity and two fistulas (fig. 1). When the mixture of iodine and normal saline was instilled

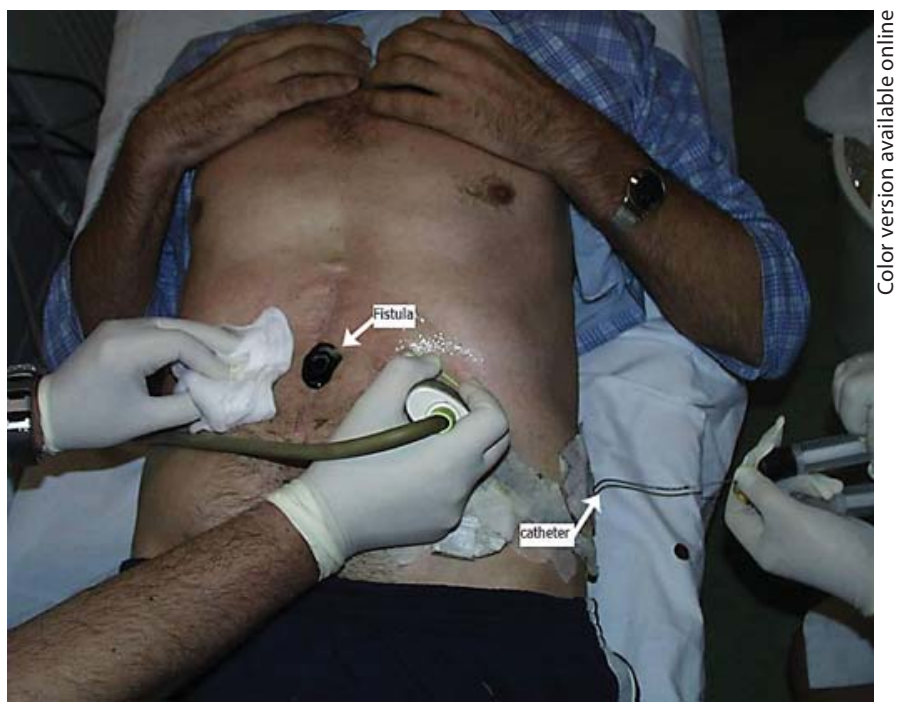

Fig. 2. Appearance of iodine via cutaneous fistula after its instillation into the abscess cavity.

through the catheter into the abscess cavity, iodine appeared via cutaneous perumbilical fistula (fig. 2) and in the stool. Abscess content revealed Escherichia coli and Staphylococcus aureus. After 43 days of percutaneous drainage and vigorous irrigation of the abscess cavity with antiseptic (iodine) and administration of proper antibiotics (ampicillin $500 \mathrm{mg}$ q.i.d., cefuroxime $750 \mathrm{mg}$ t.i.d., and metronidazole $500 \mathrm{mg}$ t.i.d.), the abscess collection and fistulas disappeared. Vigorous irrigation was performed by boluses of $50 \mathrm{ml}$ of the mixture of iodine and normal saline. Smaller necrotic fragments were carefully removed by aspiration using catheters and repeated forced flushing of the necrotic cavity with 3-4 liters of the mixture in total.

\section{Discussion}

In this case, we presented an uncommon method of managing pancreatic fistulas and retroperitoneal abscess that formed after triple necrosectomy for infected necrotizing pancreatitis. By performing percutaneous drainage with vigorous irrigation using antiseptic (iodine), retroperitoneal abscess with both internal and external fistulas were successfully treated without surgery.

Pancreatic abscess is one of the most lethal complications of acute pancreatitis because of its high morbidity and mortality $[7,8]$. It is more common in postoperative pancreatitis $(40 \%)$ than in alcoholic $(4 \%)$ or biliary $(7 \%)$ causes. The abscess develops due to superinfection of necrotic pancreatic and retroperitoneal tissues due to superinfection of acute fluid collections $[9,10]$. Several reports have shown that open surgery and immediate sur- 
gical necrosectomy for pancreatic necrosis could result in a poor clinical outcome, frequently associated with reoperations and development of complications such as infected pancreatic collections and fistulas [3-5]. Our patient underwent immediate surgical necrosectomy, which resulted in subsequent reoperations and formation of a retroperitoneal abscess and retroperitoneal-periumbili$\mathrm{cal}$ and retroperitoneal-sigmoidal fistulas.

Pancreatic fistula is usually a complication of acute or chronic pancreatitis. Many pancreatic fistulas develop after operations such as pancreatic resections or necrosectomies done for necrotizing pancreatitis [4-6]. Traditionally, pancreatic fistulas have been managed primarily by conservative treatment with total parenteral nutrition and pancreatic secretory inhibitor octreotide administration [6]. However, conservative treatment fails in many patients. Interventional therapies and even surgery are the next option. A later surgery for a fistula is technically demanding and is associated with major morbidity and mortality [6].
Contrary to several other studies $[7,10]$ ultrasound was used for diagnosis and guidance for drainage in our case. We believe that in the majority of cases, ultrasound can clearly provide the optimal depiction of abscesses, the potential insertion route for drainage, and the optimal position of catheters without risk of exposition to irradiation.

We believe that the most important factor in the success of percutaneous drainage is proper catheter management, including its manipulation and readjustment as well as frequent control examinations (often daily) after the initial catheter placement.

\section{Conclusion}

This case showed that ultrasound-guided percutaneous drainage should be considered a reasonable initial option in the spectrum of therapeutic choices for pancreatic abscesses and fistulas.

\section{References}

$>1$ Werner J, Feuerbach S, Uhl W, Büchler MW: Management of acute pancreatitis: from surgery to interventional intensive care. Gut 2005;54:426-436.

$\checkmark 2$ Beger HG, Rau BM: Severe acute pancreatitis: clinical course and management. World J Gastroenterol 2007;13:5043-5051.

$>3$ Besselink MG, Verwer TJ, Schoenmaeckers EJ, Buskens E, Ridwan BU, Visser MR, et al: Timing of surgical intervention in necrotizing pancreatitis. Arch Surg 2007;142:11941201 .
4 Zerem E, Imamovic G, Sušić A, Haračić B: Step-up approach to infected necrotising pancreatitis: a 20-year experience of percutaneous drainage in a single centre. Dig Liver Dis 2011;43:478-483.

5 Zerem E, Pavlović-Čalić N, Sušić A, Haračić B: Percutaneous management of pancreatic abscesses: long term results in a single center. Eur J Intern Med 2011;22:e50-e54.

$\checkmark 6$ Halttunen J, Kylänpää L: Treatment of pancreatic fistulas. Eur J Trauma Emerg Surg 2007;33:227-230.

-7 Sikora SS, Khare R, Srikanth G, Kumar A, Saxena R, Kapoor VK: External pancreatic fistula as a sequel to management of acute severe necrotizing pancreatitis. Dig Surg 2005;22:446-451.
8 Frey CF: Management of necrotizing pancreatitis. World J Med 1993;159:675-680.

$\checkmark 9$ Stanten R, Frey CF: Comprehensive management of acute necrotizing pancreatitis and pancreatic abscess. Arch Surg 1990;125: 1269-1275.

-10 Cantasdemir M, Kara B, Kantarci F, Mihmanli I, Numan F, Erguney S: Percutaneous drainage for treatment of infected pancreatic pseudocysts. South Med J 2003;96:136-140. 